- Bleaching gels act as effective insulators helping prevent large increases in pulpa temperatures.

- Most of the bleaching lamps tested did not raise the pulpal temperature to dangerous levels.

- Care needs to be taken when using laser based lamps at high power settings.

\title{
Surface and intra-pulpal temperature rises during tooth bleaching: an in vitro study
}

\author{
M. Sulieman, ${ }^{1}$ M. Addy ${ }^{2}$ and J. S. Rees ${ }^{3}$
}

\begin{abstract}
Objective To measure the surface and intra-pulpal temperature increases in vitro on upper and lower anterior teeth during tooth whitening procedures.
\end{abstract}

Method A thermocouple was used to measure the temperature increase on the surface of an extracted upper central incisor tooth. Intra-pulpal temperature readings were made on upper and lower central incisors, lateral incisors and canines. Four lamps recommended for tooth bleaching were tested; a plasma arc lamp, a xenon-halogen lamp, a standard halogen lamp and a diode laser lamp. Temperature measurements were made with and without the bleaching agent present on the labial tooth surface.

Results The increase in surface temperature readings ranged from $0.44^{\circ} \mathrm{C}$ (luma arch) to $86.3^{\circ} \mathrm{C}$ (laser) with no bleaching gel present. Intrapulpal temperature increases ranged from $0.30^{\circ} \mathrm{C}$ to $15.96^{\circ} \mathrm{C}$. The presence of the bleaching gel reduced temperature increases seen at the tooth surface and within the pulp.

Conclusions The increase in the intrapulpal temperature with most bleaching lamps was below the critical threshold of a $5.50^{\circ} \mathrm{C}$ increase thought to produce irreversible pulpal damage. The only lamp that produced an intrapulpal temperature increase above this threshold was the laser-based lamp and caution is advised when using this equipment.

\section{INTRODUCTION}

Tooth whitening continues to grow in popularity as an effective, non-invasive method to alter the shade of teeth discoloured by either intrinsic or extrinsic stains. Bleaching products are available for use in the surgery, at home or both. In-office systems produce the most rapid results and a number of clinical studies have shown that bleaching techniques can alter tooth colour by 8-12 shades. ${ }^{1}$

Most current in-office bleaching systems are based on hydrogen peroxide using concentrations of up to 35\% applied as a paste or gel to the tooth surface. A concentrated light source is then

\footnotetext{
1,2Division of Restorative Dentistry, Department of Oral and Dental Science, University of Bristol Dental School, ${ }^{3 *}$ Adult Dental Health Dept, Dental School, College of Medicine, Cardiff University

*Correspondence to: Professor J. S. Rees, Adult Dental Health Dept, Dental School, College of Medicine, Cardiff University, Heath Park, Cardiff CF4 4XY
}

E-mail: reesjs1@cardiff.ac.uk applied to the tooth surface to increase the reaction rate and accelerate the decomposition of hydrogen peroxide to oxygen and perhydroxyl free radicals, which are thought to bleach the teeth. Manufacturers currently produce many different types of lights for use in tooth bleaching, including halogen, plasma arc, light emitting diodes and diode lasers. ${ }^{1}$ Most of the light emitted by these lamps is within the visible spectrum, but some lamps also emit light in the near infrared or the ultraviolet spectrum. Some lights are designed solely to be used for tooth bleaching, while other lights are multipurpose, being used for bleaching and polymerisation of tooth coloured restorative materials.

Some clinicians have expressed concerns about using light as part of the bleaching process as the heat generated by the lamp could potentially lead to pulpal necrosis. ${ }^{2}$ Zach and Cohen ${ }^{3}$ related known surface temperature increases to histologically observable pulpal injury after periods of two, 14, 56 and 91 days in Rhesus monkeys. A soldering iron heated to $275^{\circ} \mathrm{C}$ was applied to the buccal surface of healthy teeth until the required temperature had been reached at the pulp wall. They found that $15 \%$ of teeth heated by $5.5^{\circ} \mathrm{C}$ and $60 \%$ of teeth heated by $11.1^{\circ} \mathrm{C}$ suffered irreversible damage. However, these threshold values have been questioned by some workers who suggest that these values should be higher. ${ }^{4,5}$

Pulpal temperature increases in relation to the curing of tooth coloured restorations is well documented and is a result of the exothermic setting reaction of the composite and the energy absorbed from the light used to initiate cure. ${ }^{4,6-10}$ Overall, these studies have reported a pulpal temperature increase of $10-14^{\circ} \mathrm{C}$ but most of the work in this area has been confined to conventional light curing units. Duret ${ }^{11}$ found, however, that a plasma arc lamp (Apollo 95E) produced an intra-pulpal temperature rise of $2.2^{\circ} \mathrm{C}$ with a four second exposure time.

Sensitivity following bleaching procedures is a well-documented transient postoperative problem that could also be related to heat induced pulpal inflammation. ${ }^{12}$ However, bleaching techniques not involving heat or light also produce sensitivity. ${ }^{13}$ There is also some anecdotal evidence that bleaching leads to pulpal necrosis.

The aim of this study in vitro was to examine the heat generated by a selection of lights used as part of the bleaching process.

\section{MATERIALS AND METHOD}

A representative number of curing lights were used in this study namely: 


\begin{tabular}{|c|c|c|}
\hline Light & Power & Spectrum \\
\hline Apolite Plasma Arc & $1628 \mathrm{~mW} \mathrm{~cm}^{-2}$ & $380-530 \mathrm{~nm}$ \\
\hline Luma Arch & $650 \mathrm{~mW} \mathrm{~cm}^{-2}$ & $380-530 \mathrm{~nm}$ \\
\hline Optilux 501 & $1000 \mathrm{~mW} \mathrm{~cm}^{-2}$ & $380-530 \mathrm{~nm}$ \\
\hline Diode Laser & $3 \mathrm{~W}$ & $830 \mathrm{~nm}$ \\
\hline
\end{tabular}

\begin{tabular}{|c|c|c|}
\hline Lamp & Minus gel ${ }^{\circ} \mathrm{C}(\mathrm{SD})$ & Plus gel ${ }^{\circ} \mathrm{C}(\mathrm{SD})$ \\
\hline Apolite Plasma Arc & $26.2(2.7)$ & $1.2(0.18)$ \\
\hline Luma Arch & $3.4(0.25)$ & $0.44(0.07)$ \\
\hline Optilux 501 & $22.7(1.4)$ & $2.7(0.35)$ \\
\hline Laser & $86.3(3.4)$ & $11.6(1.34)$ \\
\hline
\end{tabular}

- Apolite Plasma Arc (DMDS UK, Lombard House, 12-17, Upper Bridge St., Canterbury)

- Luma Arch (DMDS UK, Lombard House, 12-17, Upper Bridge St., Canterbury)

- Optilux 501 (Kerr Hawe SA, P0 Box 268, 6934 Bioggo, Switzerland)

- Diode laser (Medivance Instruments Ltd, Barretts green Road, Harlesden, London NW10 7AP)

The Apolite is a plasma arc lamp that uses a high-frequency electrical field to generate its plasma energy. The Luma arch lamp is a xenon-halogen lamp that is composed of four bulbs in a semi-circular case that is used to activate a bleaching gel applied to the upper and lower anterior arches at the same time. The Optilux 501 is a powerful standard halogen lamp and the diode laser produces an output in the near infra-red region. The power output and spectral distributions of these lamps are given in Table 1.

The temperature increase produced by each lamp was measured with a $\mathrm{K}$ type thermocouple with a positive nickel-chromium arm and a negative nickel-aluminium arm. A change in temperature between the junction of the two alloys produces a voltage that is proportional to the temperature rise. This is known as the Seebeck effect.

The voltage generated was fed into an eight channel data logger (PICO TC-08; Pico Technology Ltd, Neots, Cambridgeshire) connected to a laptop computer. The thermocouple produced a voltage of $40 \mu \mathrm{V}$ per degree Celsius. This signal was amplified by the data logger and fed into a 16-bit analog to digital converter. The data were sampled once every 40 msecs and this was fed into the Pico Log data-logging programme (Pico Technology Ltd, Neots, Cambridgeshire,) for Windows. This is a flexible data-logging package for collecting, analysing and displaying data. Data were collected at a rate of one reading every 40 msecs over the application time of each lamp.

The teeth chosen for the study were an upper and lower central incisor, lateral incisor and canine. Measurements were made either on the tooth surface or within the pulp chamber at room temperature with and without the presence of the bleaching gel on the tooth surface. Pulpal measurements were made by placing the thermocouple at the most coronal level of the pulp chamber and its position was checked using radiography (Fig. 1). The teeth were irradiated with the respective lamps according to each manufacturer's instructions. Specimens treated with the Apolite were irradiated for $3 \mathrm{~s}$; specimens treated with the Optilux or diode laser were irradiated for $30 \mathrm{~s}$ and specimens treated with the Luma Arch were irradiated for 10 minutes. Each measurement was repeated six times for each individual light on each tooth type.

The allocation of light to tooth type was randomised and at least 30 minutes was allowed between replicate applications of the same light and between each light to allow the temperature to return to baseline. This was also confirmed by reference to the thermocouple reading. For the surface study it was suspected that the tooth type would not influence the temperature rise. The method was therefore piloted with one light applied to all teeth and duplicate readings taken. This gave temperature data within a very narrow band with no obvious pattern for tooth differences. Indeed, similar readings were found when the thermocouple was placed on the work surface. The surface study was therefore carried out using the upper central incisor with six readings taken for each light with and without bleaching gel. The same 30 min period was allowed between readings with the same light or between lights.

Approximately $0.5 \mathrm{ml}$ of freshly mixed bleaching gel was applied to cover the labial surface of the test teeth. The bleaching agent (Quick white bleaching powder, Quickwhite, Canterbury) was prepared by mixing together $0.1 \mathrm{~g}$ of the quick white bleaching powder, containing fumed silica, photoactive colorants and dyes, with $0.5 \mathrm{ml}$ of 35\% hydrogen peroxide gel. The mixture was then applied to the enamel surface of the specimen to produce a uniform layer approximately $2 \mathrm{~mm}$ thick. The mixture was activated with each of the lamps placed just above the surface of the gel. The gel was removed and replaced for each temperature reading. That is, there were a total of 144 gel applications for the intrapulpal study and 24 for the surface study.

The dentine thickness at the horizontal cut surface of the tooth, which was just below the level of the amelocemental junction, was measured using electronic calipers accurate to $0.01 \mathrm{~mm}$ (Mitutoyo (UK) Ltd, Andover, Hampshire). Measurements were made from the pulpal dentine surface to the external root surface. Six measurements were made per specimen and a mean result reported.

\section{Statistical methods}

Inspection of the data indicated that the standard deviation for the different treatments with and without gels was very heterogeneous. Based on this, a pragmatic decision was made to analyse the data untransformed and with square root and logarithmic transformations. For the intrapulpal data, threeway analysis of variance was then used to test for differences between lights, tooth type and gel use together with their interactions.

Two-way analysis of variance was then performed to test for differences between light sources and gel together with their interaction.

For the surface study two-way analysis of variance was performed for differences between light source and gel together with their interaction.

Analysis of variance was also used to compare differences in the dentine thickness between the different tooth types.

\section{RESULTS}

\section{Surface study}

The mean and standard deviations of the temperature rise at the incisor surface with the four light sources with and without gel are shown in Table 2. Observationally there were large differences between the lights both with and without gel, with the lowest temperature rise seen with the Luma Arc and the largest with the laser. The gel appeared to provide considerable insulation for each light, and temperature rises were much reduced. Two-way analysis of variance revealed highly significant differences between lights $(\mathrm{P}<0.001)$ and with and without gel for each light $(\mathrm{P}<0.001)$ together with significant interaction effects $(\mathrm{P}<0.001)$.

\section{Intra-pulpal study}

The mean and standard deviation of the temperature rises in the pulp chambers of the test teeth with each light with and without 
gel are shown in Table 3. Observationally, there are mean differences in temperature rises between the three potential variables of tooth type, light source and gel use. Tooth type without gel for each light shows in most cases that upper central and lateral incisors have lower temperature rises than their lower counterparts, but canines have similar temperature rises whether upper or lower in type. When gel is included, similar effects of tooth type can be seen albeit with fewer mean differences between upper and lower incisors with the light type. Both with and without gel differences between lights are clearly apparent with the least temperature rise seen with the Apolite source and most with the laser; Luma arc and Optilux being intermediate or very similar.

The gel appeared to provide an insulating effect and temperature rises were less in all teeth across all lights when gel was applied. Three-way analysis of variance based on untransformed or transformed data sets showed the mean effects of light source, tooth type and gel together with all interactions were highly significant $(\mathrm{P}<0.001)$.

Two-way analysis of variance based on untransformed and transformed data revealed that the variation between light sources was dominant $(\mathrm{P}<0.001)$ followed by gel $(\mathrm{P}<0.001)$. The gel by light source interaction was also significant $(\mathrm{P}<0.001)$ untransformed and $\log$ transformed data; $\mathrm{P}<0.01$ square root transformed data).

The results of the variation in dentine thickness are shown in Table 5 . The values for the lower canine were significantly different from the lower central incisor $(\mathrm{p}<0.01)$ and from the lower lateral incisor $(p<0.05)$. There were no statistically significant differences between the upper anterior teeth.

\section{DISCUSSION}

This study has reported the surface and pulpal temperature readings found on upper and lower anterior teeth during simulated tooth bleaching. The surface readings were found to be much higher than the pulpal readings. This is a consequence of the relatively low values for the thermal conduction of tooth tissue particularly dentine $\left(1.36 \times 10^{-3} \mathrm{cal} \mathrm{s}^{-1} \mathrm{~cm}^{-2}\right) .{ }^{14}$ The consequence of this is that the transmission of heat in teeth occurs at a relatively low rate. ${ }^{15}$

\section{Surface study}

The increase in surface temperature obtained without the gel varied widely. The Optilux and Apolite lamps showed a similar temperature increase of $22-26^{\circ} \mathrm{C}$. In comparison, the Luma arch lamp produced a much lower surface temperature rise of $3.4^{\circ} \mathrm{C}$. The manufacturers claim that due to the presence of liquid based filters within the lamp there is virtually no heat build up and our data would seem to support this claim. Conversely, the laser diode lamp produced the highest surface temperature change at $86^{\circ} \mathrm{C}$ and this is probably due to the much higher power output compared to the other lamps (Table 1).

However, the increase in surface temperatures obtained with the bleaching gel in place is more clinically relevant. The presence of the bleaching gel reduced the increase in surface temperature dramatically, by $87-96 \%$. It therefore seems that the bleaching gel was acting as an efficient insulating layer. In addition to this the gel had large amounts of hydrogen peroxide (35\%) and water. Evaporation of both of these components could potentially produce a cooling effect that would be transmitted to the thermocouple at the tooth surface. In spite of the insulating effects of the gel, the laser diode lamp produced a large temperature increase of $11.6^{\circ} \mathrm{C}$ that could potentially cause pulpal damage. However, it should be remembered that this temperature rise was achieved with the laser set at its upper limit for bleaching.

\section{Intra-pulpal study}

The increase in intra-pulpal temperatures with the various lamps followed a similar pattern as the surface temperature increases.
Without the bleaching gel, the increase in the pulpal temperature of the Apolite, Luma arc and Optilux lights ranged from $0.3-3^{\circ} \mathrm{C}$. However, the laser diode lamp showed a much higher increase at $10.7^{\circ} \mathrm{C}$. It is also interesting to note that the smallest teeth included in this study, that is, the upper and lower lateral incisors showed larger temperature increases compared to the canine teeth. This may partly be explained by differences in the thickness of the dentine between these tooth types. The simple measurements of the dentine thickness found that the dimensions of the lower central and lateral incisors were significantly different from the lower canine. No statistical differences between the upper teeth were found. However, these measurements were only made in a single plane, just below the amelocemental junction. In reality, the dentine thickness within a tooth will vary depending on the rate at which secondary and tertiary dentine is laid down.

The addition of the bleaching gel to the system reduced the magnitude of the temperature rises, but the temperature increase with the laser diode was still significantly greater than the other lamps at $8.8^{\circ} \mathrm{C}$. The tendency for temperature increases to be greater in the upper and lower lateral incisors was again present and for some of the lamps (Plasma arc and Luma arch) the temperature increases were approximately doubled compared with the canine.

Zach and Cohen $^{3}$ found in a monkey model that a $5.5^{\circ} \mathrm{C}$ temperature rise is likely to cause irreversible pulpal damage. However, these threshold values have been questioned by some workers ${ }^{4,5}$ who suggest that these values should be higher. If the threshold value of $5.5^{\circ} \mathrm{C}$ is applied to our data then the laser-based lamp may be capable of causing pulpal damage. The reason for this large intra-pulpal temperature rise is probably related to the

\begin{tabular}{|c|c|c|c|c|c|c|}
\hline \multirow[t]{2}{*}{ Lamp } & \multicolumn{3}{|c|}{ Upper teeth ${ }^{\circ} \mathrm{C}(\mathrm{SD})$} & \multicolumn{3}{|c|}{ Lower teeth ${ }^{\circ} \mathrm{C}(\mathrm{SD})$} \\
\hline & Central & Lateral & Canine & Central & Lateral & Canine \\
\hline Apolite Plasma Arc & $\begin{array}{c}1.10 \\
(0.09)\end{array}$ & $\begin{array}{c}1.51 \\
(0.26)\end{array}$ & $\begin{array}{c}1.38 \\
(0.25)\end{array}$ & $\begin{array}{l}2.41 \\
(0.12)\end{array}$ & $\begin{array}{c}2.36 \\
(0.16)\end{array}$ & $\begin{array}{c}1.25 \\
(0.14)\end{array}$ \\
\hline Luma Arch & $\begin{array}{c}1.69 \\
(0.45)\end{array}$ & $\begin{array}{c}2.88 \\
(0.46)\end{array}$ & $\begin{array}{c}1.90 \\
(0.28)\end{array}$ & $\begin{array}{c}3.21 \\
(0.46)\end{array}$ & $\begin{array}{c}3.06 \\
(0.28)\end{array}$ & $\begin{array}{c}1.85 \\
(0.23)\end{array}$ \\
\hline Optilux 501 & $\begin{array}{c}1.83 \\
(0.08)\end{array}$ & $\begin{array}{c}2.66 \\
(0.37)\end{array}$ & $\begin{array}{c}1.87 \\
(0.06)\end{array}$ & $\begin{array}{c}3.76 \\
(0.09)\end{array}$ & $\begin{array}{c}3.71 \\
(0.25)\end{array}$ & $\begin{array}{c}1.86 \\
(0.08)\end{array}$ \\
\hline Laser & $\begin{array}{c}10.71 \\
(0.52)\end{array}$ & $\begin{array}{l}15.67 \\
(0.36)\end{array}$ & $\begin{array}{l}10.60 \\
(0.41)\end{array}$ & $\begin{array}{l}15.73 \\
(0.34)\end{array}$ & $\begin{array}{l}15.96 \\
(0.13)\end{array}$ & $\begin{array}{l}10.65 \\
(0.22)\end{array}$ \\
\hline
\end{tabular}

\begin{tabular}{|c|c|c|c|c|c|c|}
\hline \multirow[t]{2}{*}{ Lamp } & \multicolumn{3}{|c|}{ Upper teeth ${ }^{\circ} \mathrm{C}$ (SD) } & \multicolumn{3}{|c|}{ Lower teeth ${ }^{\circ} \mathrm{C}$ (SD) } \\
\hline & Central & Lateral & Canine & Central & Lateral & Canine \\
\hline Apolite Plasma Arc & $\begin{array}{c}0.5 \\
(0.05)\end{array}$ & $\begin{array}{c}0.78 \\
(0.07)\end{array}$ & $\begin{array}{c}0.30 \\
(0.02)\end{array}$ & $\begin{array}{c}0.47 \\
(0.10)\end{array}$ & $\begin{array}{c}0.64 \\
(0.07)\end{array}$ & $\begin{array}{c}0.27 \\
(0.05)\end{array}$ \\
\hline Luma Arch & $\begin{array}{c}1.24 \\
(0.32)\end{array}$ & $\begin{array}{c}2.14 \\
(0.37)\end{array}$ & $\begin{array}{c}1.39 \\
(0.20)\end{array}$ & $\begin{array}{c}2.35 \\
(0.33)\end{array}$ & $\begin{array}{c}2.26 \\
(0.21)\end{array}$ & $\begin{array}{c}1.23 \\
(0.40)\end{array}$ \\
\hline Optilux 501 & $\begin{array}{c}1.48 \\
(0.20)\end{array}$ & $\begin{array}{c}1.99 \\
(0.12)\end{array}$ & $\begin{array}{c}1.44 \\
(0.28) \\
\end{array}$ & $\begin{array}{c}2.43 \\
(0.34)\end{array}$ & $\begin{array}{c}3.00 \\
(0.20)\end{array}$ & $\begin{array}{c}1.34 \\
(0.24)\end{array}$ \\
\hline Laser & $\begin{array}{c}7.15 \\
(0.46)\end{array}$ & $\begin{array}{c}8.52 \\
(0.28)\end{array}$ & $\begin{array}{c}7.12 \\
(0.31)\end{array}$ & $\begin{array}{c}8.76 \\
(0.79)\end{array}$ & $\begin{array}{c}8.67 \\
(0.64)\end{array}$ & $\begin{array}{c}7.14 \\
(0.28)\end{array}$ \\
\hline
\end{tabular}

\begin{tabular}{l} 
Table 5 Cervical dentine thickness \\
\hline \begin{tabular}{lcc} 
Tooth & Mean thickness $(\mathrm{mm})$ & Standard deviation \\
\hline Upper central incisor & 2.33 & 0.40 \\
\hline Upper lateral incisor & 1.58 & 0.49 \\
\hline Upper canine & 2.16 & 0.51 \\
\hline & & \\
\hline Lower central incisor & 1.16 & 0.25 \\
\hline Lower lateral incisor & 1.41 & 0.66 \\
\hline Lower canine & 2.25 & 0.41
\end{tabular} \\
\hline
\end{tabular}


greater power output of the laser lamp, which at 3W, is considerably greater than the other lamps (Table 1).

However, these findings must be interpreted with a certain amount of caution. An intact pulpal blood flow will act as an efficient heat sink, with the pulpal circulation being able to dissipate some of the applied heat before pulpal cells are damaged. ${ }^{9}$ The current in vitro model was not able to replicate this, so it is possible that the $8.8^{\circ} \mathrm{C}$ intra-pulpal temperature rise recorded for the laser with lower incisors could, in reality, be less and therefore below the threshold for irreversible damage. Furthermore, the natural flow of fluid from the pulp and through the enamel and dentine was not simulated and this flow could also impede the transfer of heat to the pulpal tissues. The comments above can only be speculation since, except for the surface experiment; this type of study could not be conducted in vivo. Even a study in vivo on teeth undergoing root canal therapy would be less representative of the clinical situation than the present in vitro model. In a clinical study the thermocouple would not be totally enclosed in tooth tissues as it would be introduced through a coronal access cavity and there would be heat loss to the surrounding air introducing a potentially significant error.

In spite of these reservations, this study does demonstrate that the potential for pulpal damage with the laser is higher than for the other lamps and as such needs to be used with caution. Apart from the laser diode lamp, the other lamps show a moderate increase at the enamel surface of $0.4-2.7^{\circ} \mathrm{C}$. This begs the question of how significant this temperature rise would be as part of the treatment process and whether it is necessary to apply an intense light source at all, as hydrogen peroxide breaks down under ambient light conditions. This will form the basis of a future study.

In conclusion, this study has shown that the use of a bleaching gel is able to offer a protective insulating layer against the surface and pulpal temperature increases that accompany the use of bleaching lamps. Some caution should be exercised in the use of lasers to activate the bleach, particularly if set at high power and/or used over extended time periods.

Dr M. Sulieman is supported by a Shirley Gladstone Hughes Award

1. Clinical Research Associates. New generation in-office vital tooth bleaching. Part 2. CRA Newsletter 2003; 27: 1-2

2. Tjan A H L, Dunn J R. Temperature rise produced by various light generators through dentinal barriers. J Prosthet Dent 1988; 59: 433-438.

3. Zach $L$, Cohen G. Pulp response to externally applied heat. Oral Surg, Oral Med, Oral Path 1965; 19: 515-530.

4. Lloyd C H, Joshi A, McGlynn E. Temperature rise produced by light sources and composites during curing. Dent Mats 1986; 2: 170-174.

5. Baldissara P, Catapano S, Scotti R. Clinical and histological evaluation of thermal injury thresholds in human teeth: preliminary study. J Oral Rehabil 1997; 24: 791-801.

6. McCabe J F. Cure behaviour of light activated composites by differential thermal analysis. J Dent Res 1985; 64: 229-232.

7. Smale R J, Paterson C J, McLundie A C. In vitro temperature rise during visible light curing of a lining material and composite. J Oral Rehabil 1987; 15: 363-366.

8. Masutani S, Setcos J C, Schell R J, Phillips R W. Temperature rises during polymerisation of visible light activated composite resins. Dent Mats 1988; 4: 174-178.

9. Goodis $H$ E, White J E, Andrews J, Wanatabe L G. Measurement of temperature generated by visible light cure lamps in an in vitro model. Dent Mats 1989, 5:230-234.

10. Hussey D L, Biagioni P A, Lamey P J. Thermographic measurement of temperature change during resin composite polymerisation in vitro. J Dent 1995; 23: 267-271.

11. Duret F. Rapid photopolymerisation of dental composites by means of plasma light. 2003 www.dmdsuk.com/report01.htm (accessed 9.7.03)

12. Greenwall L. Bleaching techniques in restorative dentistry. pp 88-172. London: Martin Dunitz, 2001.

13. Russell $C M$, Dickinson $G \mathrm{~L}$, Johnson $\mathrm{M} \mathrm{H}$. Dentist-supervised home bleaching with ten per cent carbamide peroxide gel: a six month study. J Esthet Dent 1996; 8: 177-182.

14. Craig R G, Peyton FA. Thermal conductivity of tooth structures, dentine, cements and amalgam. J Dent Res 1961; 40: 411-418.

15. Longman $\mathrm{C} \mathrm{M}$, Pearson $\mathrm{G} J$. Variations in tooth surface temperature in the oral cavity during fluid intake. Biomats 1987; 8: 411-414. 